\title{
A ROTINA NA EDUCAÇÃO INFANTIL
}

\author{
Clarice Martins Monteiro de Miranda ${ }^{1}$ \\ Eleuza de Souza Borba Rezende ${ }^{2}$ \\ Jaqueline dos Santos Silvério ${ }^{3}$ \\ Neuzelene Lemes de Moraes ${ }^{4}$
}

RESUMO: Este artigo analisa o processo de educação infantil por meio da busca de literatura sobre sua aplicação, com especialistas no assunto em diversas fontes de aconselhamento, como artigos científicos, livros, publicações na Internet, diversos meios de comunicação, inclusive a Internet. $\mathrm{O}$ objetivo deste artigo é destacar a relevância dos hábitos e rotinas de aprendizagem no contexto familiar e a possibilidade de desenvolvimento de programas de aperfeiçoamento em sala de aula. Os resultados obtidos avaliam a afirmação de que o núcleo familiar desempenha um papel fundamental na aprendizagem de certos hábitos, rotinas e padrões, que podem e devem ser reforçados em sala de aula por meio de atividades educativas conduzidas por grupos de ensino. Por fim, expressaram a conviç̧ão de que os especialistas da escola colaboram em uma grande missão. Com este artigo, queremos demonstrar a importância da família quando se trata de incutir e criar hábitos saudáveis nas crianças, em colaboração direta com grupos educacionais, e tudo isso para aprender. Alunos e crianças recebem uma educação em valores e se desenvolvem plenamente sua autonomia pessoal.

Palavras-chave: Rotinas. Educação. Hábitos. Infantil.

ABSTRACT: This article analyzes the process of early childhood education through a literature search on its application, with subject matter experts in different sources of advice, such as scientific articles, books, publications on the Internet, various media, including the Internet. The purpose of this article is to highlight the relevance of learning habits and routines in the family context and the possibility of developing improvement programs in the classroom. The results obtained assess the assertion that the family nucleus plays a fundamental role in learning certain habits, routines and patterns, which can and should be reinforced in the classroom through educational activities conducted by teaching groups. Finally, they expressed the conviction that the school's specialists collaborate in a

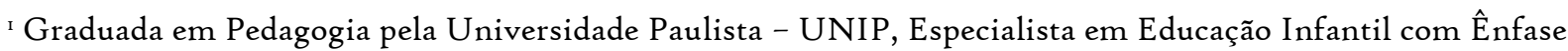
em Educaçao Especial pela Faculdade de Educação de Tangará da Serra - UNISERRA.

${ }^{2}$ Graduada em Pedagogia pelo Centro Universitário de Jales, Especialista em Educação Infantil pela Faculdade Luso Capixaba.

3 Graduada em Pedagogia pela Faculdade Afirmativo, Especialista em Educação Infantil pela Faculdade INVEST de Ciências e Tecnologias.

${ }_{4}$ Graduada em Pedagogia pelo Instituto Cuiabano de Educação, Especialista em Educação Infantil com Ênfase na Educação Especial pelas Faculdades Integradas de Cuiabá - FIC.
} 
great mission. With this article, we want to demonstrate the importance of the family when it comes to instilling and creating healthy habits in children, in direct collaboration with educational groups, and all this for learning. Students and children receive an education in values and fully develop their personal autonomy.

Keywords: Routines. Education. Habits. Children's.

\section{INTRODUÇÃO}

As normas, hábitos e rotinas que os alunos expressam em classe apontam para atitudes que constituem o ponto de partida deste trabalho para refletir sobre os mecanismos de transmissão destes valores no contexto familiar (transmissão pais-filhos) e o modo em que esta aprendizagem afeta outros âmbitos pessoais e sociais da vida da criança.

A aprendizagem deste conjunto de normas e hábitos (que incluem aspectos como a alimentação, a higiene, o sono, a autonomia, a conduta cívica e a brincadeira) têm um efeito e uma projeção imediata em aula e no trato das crianças com seus colegas de classe.

Ressalta-se o papel fundamental que desempenha a família nos primeiros anos de escolarização, já que muitos dos hábitos, as rotinas, os costumes e as normas que se adquirem na família acompanham as crianças ao longo de toda a vida. Para isso, os pais devem considerar a necessidade de inculcar em seus filhos os valores necessários para que desenvolvam estilos de vida saudáveis e elevados níveis de autonomia pessoal.

\section{DESENVOLVIMENTO}

2.I Aspectos teóricos

Nesta seção realiza-se um percurso sobre os aspectos teóricos que sustentam o tema deste trabalho expondo a opinião de alguns autores. Para fazer um pouco de história retomase Montesquieu dizendo que recebemos três educações diferentes, senão contrárias: a de nossos pais, a de nossos professores e a do mundo. O que nos dizem na última dá ao fracasso com todas as idéias adquiridas anteriormente (LA BORDERIE, 2005).

A seguir definem-se algumas das palavras que serão a base deste trabalho. $O$ que são os hábitos? Entre todas as definições que lemos, pensamos que a mais esclarecedora seja a de Barbosa (2009) ensinando que hábitos são costumes, atitudes, formas de conduta ou comportamentos que envolvem padrões de conduta e aprendizagens. $O$ hábito bem adquirido e usado permite enfrentar os acontecimentos cotidianos. 
Para Oliveira (2002) a rotina diária é para as crianças o que as paredes são para uma casa, dando limites, fronteiras e dimensão à vida. A rotina dá uma sensação de segurança. A rotina estabelecida dá um sentido de ordem do qual nasce a liberdade.

Dessa forma se estabelece a diferença que há entre rotina e hábito. A rotina, que pode desaparecer, é um costume pessoal estabelecida por conveniência e que não permite modificação, isto é, é inflexível; por exemplo, guardar a mochila e o material no lugar adequado ao chegar à classe.

O hábito, no entanto, é um mecanismo estável que cria habilidades e que ademais podem se usar para diferentes situações. Tanto as rotinas como os hábitos oferecem um componente importantíssimo de constância e regularidade e, por isso, são fundamentais tanto para a vida familiar como a escolar.

De acordo com Campos (1994) durante a Educação Infantil as crianças devem ir aprendendo (assimilando) normas ou padrões de conduta, comportamentos que são habituais em seu meio ambiente. Na etapa infantil, na hora de educar, é de maior interesse a criação de bons hábitos do que chegar a possuir amplos conhecimentos.

Para Oliveira (2002) na hora de criar hábitos são essenciais cinco passos: decidir o que se quer que faça ou o que se vai pedir à criança; chegar até o final com as coisas com firmeza e amabilidade; não falar, mas agir; cumprir sempre o prometido até o final; e menos é mais: deixar que as atuações falem mais alto que as próprias palavras.

No momento de adquirir hábitos deve-se considerar que é um processo contínuo, gradual e dura toda a vida; precisa de um processo satisfatório e agradável para o sujeito devendo produzir sucesso (sobretudo num primeiro momento) e ser reforçado no momento oportuno.

A família deve ter paciência e ser precisa nas descrições das condutas onde os pais devem colaborar e marcar normas claras indicando um ambiente relaxante, tranquilo e adaptado para que a criança deseje colaborar, havendo para isso motivação.

Durante os primeiros anos de vida, os pais desempenham um papel fundamental na transmissão a seus filhos de valores, normas, hábitos, rotinas e costumes. Este conjunto de atitudes será fundamental para seu desenvolvimento pessoal e social e em muitas ocasiões, terão um caráter persistente no tempo. Durante esta idade, compreendida entre os 
3 e 5 anos, a aprendizagem opera através de dinâmicas de reforço e castigo, e mediante condutas de imitação em figuras "modelo".

Com frequência, estes papéis são assumidos pelos progenitores, com quem as crianças desenvolvem sinergias de identificação. À medida que passa o tempo, outras figuras, como irmãos ou amigos, irão assumindo esse papel, como são demonstrados por diversos trabalhos de pesquisa, apontados neste artigo.

A incorporação da criança na escola, as condutas de imitação aprendizagem coincidem em vários contextos: em sua relação com os progenitores e na aula, que influi paralelamente à ação dos pais. Portanto, a relação família-escola é essencial para um desenvolvimento harmônico. Pais e professores elaboram padrões de atuação conjuntos e coordenados, encaminhadas a favorecer a aquisição de hábitos básicos para sua autonomia e desenvolvimento posterior.

Os filhos são total responsabilidade dos pais e se desejamos que sua integração social seja exitosa, devemos os acompanhar durante todas as fases do crescimento com condutas exemplares.

A literatura científica que avalia o modo em que os maus hábitos durante a idade precoce afetam o crescimento. É óbvio que os primeiros educadores estão na Família. De forma complementar, a escola oferece novas condutas e reforça determinadas aprendizagens que não ocorrem em um contexto familiar.

Se os pais não desenvolvem com regularidade atitudes proativas e pró sociais, seus hábitos de higiene e alimentação são deficientes e se o sono não se regula de acordo com fórmulas saudáveis, estarão oferecendo um "modelo" diferente ao que promovem as escolas

Ao contrário, se a família impulsiona hábitos de vida saudáveis, ensinando seus filhos os benefícios de fazer exercício da prática do esporte, de descobrir o sabor de novos alimentos, daremos um bom exemplo a imitar e a criança, seguramente, adotará os mesmos hábitos.

Mas, as condutas pró sociais podem ser aprendidas? Segundo Carvalho (2016), as condutas de cooperação, de ajuda, podem se aprender seguindo três processos: por um lado, um processo de identificação (sobretudo dos pais); por outro, um processo de imitação dos diferentes modelos de comportamento (pais, mestres, colegas) e finalmente, a partir da prática na família, na escola e na sociedade em geral. 
Piaget (1975) ensinava que para aprender física ou linguagem é necessário fazer experimentos e analisar textos, para aprender a viver em coletividade precisa-se ter experiências de vida em comum.

Considera-se que podem se propor diversas atividades para as crianças nas quais através da estimulação cognitiva da prática em atividades programadas e das vivências reais, possam experimentar situações de relação social.

O papel da família como agente socializador é sem dúvida o que lhe confere um papel decisivo no conjunto da estrutura social, pois é dentro do ambiente familiar que a criança começa a tomar contato com o mundo exterior, e onde sua personalidade começa a adquirir forma. Neste sentido, as modernas correntes psicopedagógicas tendem a ressaltar a importância que para o desenvolvimento harmônico do ser humano representa a existência de um equilíbrio emocional e afetivo durante sua infância, equilíbrio que só poderá se conseguir mediante a adequada coordenação entre as instituições sociais e os pais; a estes, pois, corresponde em grande parte a tarefa de proporcionar a seus filhos a formação e o apoio indispensável para que possam executar sua plena integração na sociedade.

Finalmente, se queremos que as crianças aprendam e desenvolvam bons hábitos, os pais deverão servir de exemplo e modelo para eles. A partir de um ponto de vista genérico, entende-se por rotinas aquelas atividades que se realizam diariamente de forma regular, periódica e sistêmica com um caráter inevitável. Quanto aos hábitos, considera-se que são modos de agir que se aprende e/ou se adquire com a intenção de satisfazer as rotinas e que, através deles, pode se sentir mais seguros no modo de fazer diante de diferentes situações.

É por isso que, instaurar rotinas e hábitos adequados durante a etapa de Educação Infantil permite desempenhar importantes funções em relação à configuração do contexto educativo mediante o sequenciamento espaço-temporário das aulas através da repetição de atividades e tarefas.

A LDB - Leis de Diretrizes e Bases - estabelece os ensinos mínimos da Educação Infantil como uma das três áreas curriculares a trabalhar o conhecimento de si mesmo e a autonomia pessoal. Portanto, para promover a aquisição progressiva da autonomia nas atividades habituais dos alunos, e para Faria e Palhares (1999), as principais funções que se desenvolvem ao trabalhar rotinas e hábitos no ambiente infantil seriam: 
- Oferecer um marco de referência. Uma vez que se aprendeu a correspondente rotina, a criança é capaz de se concentrar no que está fazendo sem pensar nem se preocupar no que virá depois.

- Gerar segurança, uma vez que se trata de uma atividade conhecida por quem a realiza.

- Agir como indicador temporal, já que oferece uma percepção sensorial dos diferentes momentos nos quais se deve efetuar a atividade permitindo saber o que se deve fazer antes e depois.

- Potenciar processos de captação cognitiva, referida às diferentes estruturas que apresentam as diferentes atividades a realizar.

- Desenvolver virtualidades cognitivas e afetivas a nível metodológico com motivo das possibilidades de aprendizagem posterior que terão as crianças com respeito à aquisição de estratégias de planejamento e organização das aprendizagens.

Deste modo, deve-se considerar as rotinas como puras aprendizagens que oferecem uma melhora da capacidade cognitiva, pelo qual se trata de processos que o aluno deve aprender no ambiente da classe e a família deverá considerar para estabelecer rotinas no lar que sem dúvida contribuirão para o desenvolvimento psicológico de seus filhos.

Agora, como toda aprendizagem, e mais se tratando de alunos da Educação Infantil, é necessário fixar padrões metodológicos que contribuam para organizar e sistematizar estas aprendizagens adequadamente seguindo sempre a mesma ordem nas atividades e mencionando claramente e com certa frequência por parte do professor o nome da rotina a trabalhar.

Igualmente, poderia ser interessante estabelecer um signo explícito que marque a transição de uma fase a outra pára que as crianças identifiquem claramente a mudança de atividade que se vai produzir.

Quanto à sequência ideal para a aprendizagem de rotinas e hábitos nesta etapa educativa, é importante incidir em que deveria incluir diferentes tipos de atividades para promover a generalização das aprendizagens a ambientes não estritamente educativos.

Segundo Oliveira (2002) estas atividades poderiam ser:

- Individualizadas, em pequeno grupo e em grande grupo.

- Realizadas independentemente pelos alunos. 
- Apoiadas pelo professor ou pelos adultos.

- Com envolvimento de desgaste físico e de quietude e relaxamento.

- Realizadas em ambientes interiores e exteriores.

- Relacionadas com a própria limpeza e da classe.

Por outro lado, cabe destacar que as rotinas em Educação Infantil não devem se trabalhar como elementos rígidos e impositivos, mas como procedimentos de estruturação já que contribuem a criar um contexto de segurança através da conservação e manutenção de padrões. Deste modo, quando as crianças vão assumindo as atividades habituais, irão ganhando em possibilidades de introduzir matizes para sua realização (BARBOSA, 2009).

É nesta dinâmica de flexibilização de padrões, e inclusive nas dificuldades ocasionais que possam sobrevir que contribuirão suas próprias aprendizagens e formas de resolução (por exemplo: uma atividade que se alonga mais do que o previsto, uma roupa nova que não se sabe abotoar, um instrumento cujo uso desconhece, etc.).

Dessa forma, diferentes autores concordam em identificar como as principais rotinas a trabalhar na Educação Infantil, tanto em nível curricular como a maneira de educação transversal e no lar, conforme segue (CAMPOS, 1994; BARBOSA, 2009; OSTETTO, 2008; HORN, 2009)

\subsection{Ordem e organização}

A ordem, não somente referida ao ambiente físico, como também ao temporal através dos horários. A importância deste hábito vem marcada basicamente porque a organização e a ordem em sua vida cotidiana se refletirão em sua organização interior, o que proporcionará um maior nível de segurança que permitirá se orientar e desenvolver sua inteligência melhorando significativamente seu rendimento acadêmico.

Quanto a ordem do ambiente, não se trata de respeitar a ordem estética ao gosto dos adultos, mas de estabelecer um lugar para cada coisa facilitando sua disciplina interna. Algumas das condutas a considerar para contribuir e melhorar a organização do aluno são indicadas por Horn (2009):

- Estabelecer um horário o mais ordenado e claro possível respeitando-se ao máximo por todos. 
- Organizar a classe estabelecendo um lugar para cada coisa e a seu alcance.

- Não amontoar materiais escolares nem jogos.

- Ensinar os alunos a pegar os brinquedos no seu lugar, a utilizá-los e a voltar a guardá-los no mesmo lugar.

- Estabelecer normas e limites com respeito ao horário, ordem e comportamento do aluno em classe de forma que tenham claro a todo o momento o que podem fazer e o que não devem fazer.

\subsection{Higiene}

Algumas das atividades cotidianas relacionadas com a higiene que podem se trabalhar na Educação Infantil e são as seguintes, de acordo com Barbosa e Horn (2009):

- Controle de esfíncteres.

- Utilização correta do vaso sanitário.

- Lavar as mãos, rostos e dentes.

- Deixar limpo a pia e o vaso sanitário após utilizá-lo.

- Assuar o nariz, tossir, espirrar, pentear-se adequadamente.

Quanto à metodologia a empregar em classe para trabalhar estes hábitos Barbosa e Horn (2009) sugerem:

- Programar um tempo determinado para ensinar os hábitos de higiene em aula.

- Situar os alunos em semicírculo.

- Dramatizar a sequência de ações para a utilização do vaso sanitário, do lavabo e o asseio de forma autônoma.

- Realizar atividades para aprender cada movimento, tais como: cortar papel, dobrar as mangas, limpar a pia, fechar a torneira, etc.

- Utilizar o reforço positivo para motivar os alunos na aprendizagem.

- Aceitar os possíveis erros e ajudar-lhes a retificá-los.

- Felicitar-lhes explicitamente quando consigam a aprendizagem. 
2.4 Roupas

Habitualmente, as crianças na Etapa de Infantil não chegam a assumir a responsabilidade de se vestir nem de cuidar suas roupas, deixando esta tarefa nas mãos dos adultos. No entanto é essencial trabalhar aspectos da vestimenta nestas idades para atingir um maior nível de segurança neles próprios.

Algumas das atividades que se podem trabalhar no ambiente da classe neste sentido são indicadas por Oliveira (2002):

- Calçar e descalçar os sapatos. Tirar e colocar as meias.

- Tirar e vestir a blusa ou a camisa.

- Tirar e vestir a roupa de abrigo.

- Abotoar e desabotoar os botões.

- Subir e baixar um zíper.

- Amarrar e desamarrar os cadarços.

2.5 Alimentação

$\mathrm{Na}$ verdade, o hábito de se alimentar não é apenas referido a que as crianças saibam utilizar os talheres sem ajuda, mas que aprendam a comer de tudo, que saibam comer a quantidade que cada um precise e que o façam no tempo estabelecido, o que dificulta em maior medida a aquisição do hábito em seu conjunto.

Schmitz et al. (2008) indicam algumas atividades que podem ser trabalhadas em

relação aos hábitos na alimentação podem ser:

- Utilização dos talheres (colher, garfo, faca).

- Descascar a fruta com as mãos.

- Abrir recipientes.

- Beber no copo.

- Servir-se da comida e da água.

- Utilizar o guardanapo.

- Recolher a mesa e os utensílios utilizados. 
Igualmente, também se podem promover algumas normas de convivência associadas aos alimentos tais como:

- Comer sem levantar-se da mesa.

- Mastigar com a boca fechada.

- Esperar sua vez.

- Não invadir o espaço alheio.

- Comer cada um, a sua refeição.

- Não brincar com o alimento.

\subsection{Descanso}

As crianças, igual aos adultos, devem compartilhar estados de agitação e atividade com estados de descanso, por isso é imprescindível estabelecer rotinas que favoreçam as crianças a irem para a cama, tranquilos e sempre na mesma hora.

A partir da sala de aula, algumas das atividades que podem ser realizadas para criar a rotina e o ambiente de repouso são indicadas por Debortoli (2008):

- Estabelecer um espaço da manhã em que tenham que relaxar-se (normalmente costuma coincidir com o último período letivo antes de sair do colégio).

- Colaborar na preparação e recolhida de colchonetes e almofadas.

- Calçar e descalçar-se.

2.7 Convivência

Desde o nascimento, as crianças vivem com outros seres humanos com os quais precisam se comunicar e conviver, motivo pelo qual se torna necessário trabalhar desde o ambiente educativo algumas normas sociais que contribuam para uma convivência mais agradável para todos.

Maluf (20II) destaca alguns hábitos:

- Cumprimentar, saudar e despedir-se.

- Dizer: "por favor" e "obrigado" ao pedir algo.

- Subir e descer as escadas considerando outras pessoas.

- Esperar a vez na fila. 
- Comportar-se nos transportes públicos.

- Atravessar uma rua, passear pelas ruas, etc.

- Não gritar, etc.

- Pedir permissão.

- Aprender a compartilhar.

- Colocar-se no lugar de outro (empatia).

2.8 Rituais familiares

A família que realiza rituais que envolvem todos seus membros gera um ambiente de segurança e confiança onde as crianças vão ordenando sua vida e seus próprios atos. Sem a existência destas regras as crianças sentem-se instáveis, desenvolvem medos ou, inclusive, comportamentos tiranos.

Deve se lembrar que uma educação totalmente livre não garante crianças felizes. A família deve favorecer a criação de atos habituais que todos conheçam e cumpram. Alguns exemplos destes rituais familiares são: comer juntos na mesa, colaborar em colocar e recolher a mesa, regular a hora de dormir, etc (CRESPO, 20II).

Criar rotinas ajuda a desenvolver hábitos e atitudes que serão a fonte da formação do caráter. A rotina ajuda à aquisição de hábitos e estes facilitam a realização de atividades cotidianas como estudar, se alimentar e dormir. A carência destes hábitos produz um grande desgaste emocional em conflitos e discussões, tanto para os pais como para os filhos (FERNANDES, BOEHS e RUMOR, 2012).

A implantação de rituais familiares deve-se iniciar cedo com os filhos. Desde pequeno, a criança deve habituar-se a cumprir certas regras. Desta forma, sabem o que fazer o que se espera deles e, o mais importante, vivem num ambiente onde podem se predizer o que vai passar se forem ou não cumpridas as regras estabelecidas.

Estes rituais são a base para a criação dos hábitos que possuirão a partir da adolescência e que abarcarão qualquer aspecto de sua vida. Sobretudo, deve se lembrar que as crianças aprendem melhor se os adultos derem o exemplo.

Os atos habituais ficam de alguma maneira gravada na memória proporcionando uma verdadeira educação tanto aos pais como aos filhos. E se ademais, existe colaboração 
entre a escola e os pais, será viável estabelecer programas e estratégias que facilitem a formação do caráter de crianças e jovens.

Importante ressaltar que quando a ação educativa direta planeja desafios e se fazem propostas, geralmente aparecem as "famílias" pelo qual as atividades com as famílias não podem ser um fim em si mesma (CRESPO, 2012).

Zabalza (2009) oferece sobre este tema, uma série de nuances importantes. Por um lado afirma que o valor de boas relações entre a família e a escola, resulta no bem-estar da criança. Por outro lado, adverte que o rótulo "pais" apresenta uma uniformidade enganosa sendo conveniente planejar o momento de executar as atividades como a hora de valorizar o que parece que há detrás do que se denomina colaboração.

O autor compartilha com a família o trabalho educativo, completando e ampliando suas experiências formativas. A eficácia depende, em grande parte, da unidade de critérios educativos nos diferentes momentos da vida da criança, em casa e na escola. Para que isto seja possível é necessária a comunicação e coordenação entre educadores e pais.

O modelo educativo de atuação que proporcionam os adultos, tanto em casa como na escola, é um modelo fundamental para que as crianças desenvolvam atitudes de ajuda e colaboração, de higiene e manutenção da saúde, bem como de não discriminação para as diferenças de identidade e características dos demais.

\section{CONCLUSÃO}

Os hábitos são um grande fator na construção do caráter de uma criança. Além disso, eles se identificam com o grupo social em que cresceram, seus valores e cultura, e fornecem uma estrutura sólida a partir da qual apoiar os processos de desenvolvimento do pensamento. Hábitos e rotinas também são uma fonte intransponível para reforçar comportamentos de autocontrole.

Os hábitos devem ser estáveis e formar um quadro de referência para certas situações, a fim de funcionarem como ambientes familiares próximos em que as crianças se sintam confortáveis e seguras. Adquirir bons hábitos durante esse período os deixará mais seguros, no controle e com mais auto estima.

Os pais precisam estar cientes dos benefícios da atividade física para seus filhos, especialmente em uma idade jovem, quando as habilidades motoras são a base do 
desenvolvimento. Portanto, devem estimular sua prática, independentemente das necessidades individuais ou específicas, e não se limitar à proteção superinibitória.

Os pais também devem estar cientes de que o desempenho escolar é prejudicado quando eles não restringem seu acesso ou tempo gasto na televisão, videogames, consoles de videogame, Internet, etc. e o desenvolvimento da aprendizagem, obviamente produz resultados acadêmicos ruins.

Os pais devem controlar programas, jogos e outros tipos de ambientes que produzem informações adequadas à idade. Embora estejamos falando de longo prazo, na idade dessas crianças (3-6 anos), é necessário criar hábitos saudáveis para evitar novas exposições.

Constatou-se que os hábitos devem ser trabalhados, de forma paralela e complementar, sob critérios de proximidade e colaboração, nos dois principais contextos da vida das crianças: o ambiente escolar e o contexto familiar. Somos conscientes de que a verbalização dos hábitos ajuda a sua automatização.

As crianças precisam seguir determinadas rotinas, padrões e normas de comportamento para sentir-se seguros, confiantes e tranquilos em seu ambiente. Também os hábitos ajudam a atingir certos níveis de equilíbrio emocional, que proporcionarão os mecanismos necessários para sua educação e a construção de sua personalidade.

Toda a literatura científica avalia que as idades precoces operam como um momento decisivo para incorporar e reforçar novos hábitos.

É fundamental assegurar a atividade e valiosa participação dos pais no processo educativo das crianças. A família e a escola perseguem um objetivo comum: colaborar de maneira ativa e estreita em sua formação e desenvolvimento. Para conseguir este desafio a comunicação e a coordenação são importantes, já que asseguram coerência e eficácia em todo o processo educativo.

A escola infantil, o colégio e a instituição educativa em geral não fariam sentido sem a presença ativa e constante dos pais, agentes educativos externos ao centro e base concreta sobre o qual se assenta o trabalho da instituição escolar.

É na família que se realiza as primeiros e principais aprendizagens cognitivas e emocionais, que permitem as crianças acessar, desde o afeto, ao entendimento e apreensão do funcionamento do ambiente e da sociedade. 
Os pais fornecem conhecimentos essenciais sobre como priorizar opções e padrões de vida. No fluxo das relações familiares cotidianas, são comunicadas mensagens sobre o valor atribuído às coisas, eventos, eventos e pessoas, e o grau de importância atribuído às atividades diárias.

É a formação do juízo, a distinção entre o que é importante e o que é contingente, entre o que é necessário e o que é opcional, que são elementos da própria personalidade que se constitui com pais, educadores e professores como modelos para ambos no relacionamento. Em suma, a criança é educada principalmente na família, com os pais e a família em geral. Especialistas em escolas colaboram em uma missão para a qual são convidados por pais adultos.

O trabalho educativo inclui ajudar os alunos a estruturar a aprendizagem no seio da família, contribuindo para a personalização ao longo da vida escolar e ampliando a autonomia pessoal, iniciada no seio familiar, para ambos os lados da experiência social mais complexa e fora do Círculo Familiar.

O contributo do corpo docente para o alicerce de uma relação de confiança mútua entre a casa e a escola é considerado benéfico, no sentido de garantir um maior acesso e sucesso educativo.

\section{REFERÊNCIAS}

BARBOSA, Maria Carmen Silveira. Por amor e por força: rotinas na educação infantil. São Paulo: Artmed, 2009.

BARBOSA, Maria Carmen Silveira; HORN, Maria da Graça Souza. Projetos pedagógicos na educação infantil. São Paulo: Artmed, 2009.

CAMPOS, Maria Malta. Educar e cuidar: questões sobre o perfil do profissional de educação infantil. MEC/SEF/Coedi. Por uma política de formação do profissional de educação infantil. Brasília: MEC/SEF/Coedi, 1994.

CARVALHO, José Sérgio. Podem a ética e a cidadania ser ensinadas? Pro-posições, v. I3, n. 3, p. 157-168, 2016. 
CRESPO, Carla. À mesa com a família?: Rituais familiares ao longo do ciclo de vida. Famílias: Questões de desenvolvimento e intervenção. Porto: Livpsic, 201 I.

DEBORTOLI, José Alfredo Oliveira. Reflexões sobre as crianças e a educação de seus corpos no espaço-tempo de Educação Infantil. Revista Paidéia, v. 5, n. 4, 2008.

FARIA, Ana Lúcia Goulart de; PALHARES, Marina Silveira. Educação infantil pós-LDB: rumos e desafios. Cadernos de Pesquisa, n. I07, p. 253-254, 1999.

FERNANDES, Gisele Cristina Manfrini; BOEHS, Astrid Eggert; RUMOR, Pamela Camila Fernandes. Rotinas e rituais familiares: implicações para o cuidado. Ciência, Cuidado e Saúde, v. Io, n. 4, p. 866-871, 2012.

HORN, Maria da Graça Souza. Sabores, cores, sons, aromas: a organização dos espaços na educação infantil. Artmed Editora, 2009.

LA BORDERIE, René. Grandes nomes da educação (Os). São Paulo: Edições Loyola, 2005.

MALUF, Angela Cristina Munhoz. Atividades lúdicas para Educação Infantil: conceitos, orientações e práticas. São Paulo: Editora Vozes Limitada, 201 I.

OLIVEIRA, Zilma de Moraes Ramos. Educação Infantil: fundamentos e métodos. Cortez Editora, 2002.

OLIVEIRA, Zilma de Moraes Ramos. Educação Infantil: fundamentos e métodos. São Paulo: Cortez Editora, 2002.

OSTETTO, Luciana Esmeralda. Educação infantil. São Paulo: Papirus, 2008.

PIAGET, Jean . A construção do real na criança. Rio de Janeiro: Zahar, 1975.

SCHMITZ, Bethsáida de Abreu Soares et al. A escola promovendo hábitos alimentares saudáveis: uma proposta metodológica de capacitação para educadores e donos de cantina escolar. 2008.

ZABALZA, Miguel A. Qualidade em educação infantil. São Paulo: Artmed Editora, 2009. 